\title{
Infertility in Sub-Saharan Africa: A Woman's Issue for How Long? A Qualitative Review of Literature
}

\author{
Nathan B. W. Chimbatata1, Chikondi Malimba ${ }^{2}$ \\ ${ }^{1}$ Mzuzu University, Mzuzu, Malawi \\ ${ }^{2}$ Kamuzu College of Nursing, University of Malawi, Lilongwe, Malawi \\ Email: natchims@yahoo.com
}

Received 23 July 2016; accepted 21 August 2016; published 24 August 2016

Copyright (C) 2016 by authors and Scientific Research Publishing Inc.

This work is licensed under the Creative Commons Attribution International License (CC BY). http://creativecommons.org/licenses/by/4.0/

(c) (i) Open Access

\begin{abstract}
Infertility or childlessness is a major reproductive health issue for females as well as males respectively. Many couples suffer from infertility worldwide and in Sub-Saharan Africa, which has a cultural preference for high fertility; women shoulder the highest infertility consequences. The objective of this review was therefore to explore socially acceptable and culturally effective reproductive health strategies for the social management of infertility in sub-Sahara Africa. Different databases were searched to source articles on infertility in Sub-Saharan Africa. The databases included Medline, Pubmed and Fudan University library. Google scholar was also utilized to get additional relevant articles. Titles and abstracts of the articles searched were critically evaluated for relevance based on the inclusion criteria. Final extraction of the articles was done by getting only those studies that met the inclusion criteria. Twenty articles were identified and five were included in this review. The findings reveal three main themes: perception, health seeking behavior and the social impact of infertility. In many Sub-Saharan Africa societies, there is negative perception of infertility problem as such those affected do not seek medical attention early. There is also a disproportionate social impact of infertility on women in the region. In Sub-Saharan Africa, high value is placed on children and those who are infertile are greatly stigmatized. In such a setting, the concept of reproductive health should include policies which could make it possible for couples and the whole society aware of the reality of infertility as a reproductive health problem and seek medical attention early.
\end{abstract}

\section{Keywords}

Infertility, Sub-Saharan Africa, Social Impact, Women 


\section{Introduction}

Infertility or childlessness is a global reproductive health issue for female as well as male sexes yet often not discussed in public and most of the times neglected especially in an African setting. It is generally believed that more than 70 million couples suffer from infertility problem worldwide and this constitutes $15 \%$ of reproductive aged couples globally [1]. In Sub-Saharan Africa region, infertility problem prevalence varies from $9 \%$ in Gambia [2], 21.2\% in northwestern Ethiopia [1] [3], between $20 \%$ and $30 \%$ in Nigeria [4] [5] and $11.8 \%$ among women and $15.8 \%$ among men in Ghana [6], however, men are mostly excluded in infertility discourse [7]. World Health Organization (WHO) demographic studies also show that in Sub-Saharan Africa, more than 30\% of women aged 25 - 49 years suffer from secondary infertility, the inability to achieve a subsequent pregnancy.

Infertility has been defined as failure to achieve pregnancy after one year of exposure to pregnancy risk or after one year of regular unprotected sexual intercourse in the absence of known reproductive pathology [8]. This inability to reproduce has negative implications on women especially in Sub-Saharan Africa where high fertility is preferred [9].

In the African culture, the exact meaning of marriage is mainly fulfilled if the couple conceives and bears children [10]. Africans consider their children to be a source of power and pride, and children act as a potential source of support for their parents in old age. The other major aspect of child bearing is that it is an assurance of family continuity. This aspect creates the view of child sex preference in families, for example in some parts of Malawi, a male child is preferred to a female child just because it's the boy child that would ensure the continuity of the family name.

Infertility is socially constructed in many African cultures, that is, men and women are viewed and perceived to become parents and that women are especially socialized to become mothers in society [11]. This is an explicit contrast to other societies in the west and the affluent world where individuals would choose not to have a child or just to have them by adoption. Infertility is both a social as well as a medical problem. It is a problem in social contexts because we live in a society where womanhood and manhood are generally associated with childbearing. The medical literature has revealed that the causes of infertility affect both men and women. Growing evidence from social and medical sciences highlights that nearly $40 \%-50 \%$ of infertility is mostly associated to problems affecting men. The causes of infertility may be associated with male factors $(40 \%)$, female factors $(40 \%)$ or the combination (20\%) of problems [12] [13]. A study conducted in Bawku in Northern Ghana identified tubal damage, male factor, anovulation and uterine factors as the main causes of infertility. The study also states that about $20 \%$ of infertility in Northern Ghana was due to male factors [1].

Despite these views on the causes of infertility and the realistic statistics of the causes of infertility which shows it affects both sexes, women still endure the worst of the blame for infertility problems [14] [15]. Regardless of its medical origins, infertility causes African women personal grief because it's the woman who is seen pregnant and nursing a child and infertility problem is therefore greatly manifested from the woman perspective in society. It is against this background and more specifically in Sub-Saharan Africa-a high fertility context that this review was carried out to critically examine the following questions:

- Should women continue to suffer for something they never choose to have?

- Should men in sub-Saharan Africa continue keeping themselves out of the infertility circle?

- Should sub-Saharan African society continue viewing women as child manufacturing machines?

\section{Methods}

\subsection{Inclusion and Exclusion Criteria}

The review included original peer reviewed articles conducted in Sub-Saharan Africa. The studies were supposed to address the infertility issue in the region with more emphasis on social impact of the problem in order to be included in the review.

\subsection{Data Sources}

Different databases were searched to get different articles on infertility in Sub-Saharan Africa region. The databases searched included Medline, Pubmed and Fudan University library. Google scholar was also utilized to get additional relevant articles. Titles and abstracts of the articles searched were critically evaluated for relevance based on the inclusion criteria. Final extraction of the articles was done by getting only those studies that met the 
inclusion criteria. The terms used during the search were infertility and Sub-Saharan Africa, fertility, and women and reproductive health.

\subsection{Data Extraction}

The literature search yielded 767 articles which were further screened for eligibility. After the screening, 20 full text articles were obtained and only 5 met the inclusion criteria and were included in this review.

\section{Findings}

The articles included in the review are all qualitative studies and there were three main themes that came out from most of the studies and the findings are summarized in the sections below.

\subsection{Perceptions}

Several perceptions arose from the literature. The perceptions towards infertility are from the gender as well as society point of view. In many societies infertility is viewed and perceived as women's business. The woman is blamed, not only by her partner but also the relations and by herself, for the problems that the couple faces with childbearing. She shoulders the greatest burden of social stigma and suffering caused by infertility as it is traditionally perceived as her problem. Life without children was perceived not worth living as there will be no one to inherit the properties of the deceased and that there will be no continuity of the family name [16].

"Children are the ones who sustain the generation and they inherit property ... We live on earth just because of them and they make you feel great, it is great success on earth ... People are given respect in this society because of children specifically male children." (Man participant FGD)

There was also a perception that infertility denies an individual some community rights in some sub-Saharan African communities. In such societies, one of the reasons for bearing children is to have a respectful burial ceremony, as there are significant differences in the funeral ceremonies for people with children and those without. Elderly people without children are more likely to miss most rituals in traditional communities and their funerals do not have the needed attention it deserves as compared to those with children. This in some societies is particularly more distinct for females than males without children. This is because of women's traditional role to beget children to the family of the in-law. There were also different perceptions regarding the cause of infertility from the articles:

"Prostitute women when they were young or those who were using contraception to avoid becoming pregnant ... they become infertile and trouble their spouses, they move from hospital to hospital in search for a child." (Woman participant, infertile)

Blame game perceptions regarding infertility were also common from the articles:

"Your colleagues will definitely understand you, however the parents of your husband would like to have grandchild and the mother in law will subject you to all sorts of accusations even if the man may be the one with the infertility problem." (Woman participant)

The articles also had different views on the definition of infertility and in one setting it was defined as:

"Infertility is the inability to give birth to the number of children that one would want to have and most specifically male children." (Participant in one FGD)

This clearly indicates the significance of male children in some settings that couples without male children are treated in the same way as those who do not have children at all.

\subsection{Health Seeking Behavior}

A wide range of health seeking practices arose from the articles. Most of the people use three treatment seeking strategies: churches (spiritualists), traditional healers and hospitals (biomedical). There was a strong indication that people mostly use the three treatment methods in combination and in sequence. Nonetheless, however, the 
modern hospital alternative for infertility management is not used instantly since biological factors are not perceived as imminent causes of infertility in the community and also because of the way the infertile couples are treated in the modern hospitals.

The affected couples may opt for traditional assistance and not modern hospitals just because the hospitals have the capacity to identify men as responsible for the problem and this would subject them to social blame [8].

It was also observed under this theme that the role of infertility care seeking is in most cases left to women.

Mostly women go to seek help in the clinic without their partners mostly the men refuse examinations, because they fear of being found with the problem of the couples' inability of bearing children [8].

It is worth noting that men's involvement in infertility care is supportive in other settings.

"My partner is supportive, does not torture me and gives me hope and I feel good when I talk infertility problem with him." (Woman participant with infertility problem)

The findings of many articles also show that infertile men and women with higher income are more likely to seek infertility care. This just indicates that financial status play a role in treatment-seeking behaviour for infertility couples.

\subsection{Social Impacts}

The articles have revealed several social implications that infertile individuals are subjected to in society. Given the value placed on children in sub-Saharan Africa, the infertile couples mostly experience difficult marital relations which often times than not results in domestic violence, permanent separation or divorce [17]. The events surrounding childless women are more likely of perpetual separations, divorce and sometimes remarrying; a wife could go away because of her husband's ill treatment and torture from others or even because of her husbands' demand that she should go away since she is helpless.

The articles have also shown that couples with infertility often face social stigmatization and are publically isolated. They mostly suffer abuse physically, and in more extreme terms they may even plan to harm themselves through committing suicide. Domestic violence and dissolution of marriage occur significantly more often among the infertile couples compared with couples in fecund relationships. Childless couples also face economic hardship as well because many families in developing countries depend on their offspring for economic survival. These couples feel a deeper sense of guilt, shame, and worthlessness. Women, in most cases face economic deprivation, isolation, risk of polygamy, and domestic violence. In some instances if the male is the one found with infertility problem, there are sometimes social strategies put in place like using boyfriends or bearing children with a brother-in-law. This could shield the man from the problem unlike his woman counterpart. Torture of couples with a fertility problem is a common experience from society:

"As one employed man explained, his relatives would invite him to meetings and persuade him to have his wife divorced and possibly remarry. The wife's relatives would also tell her if you want to stay in marriage make yourself pregnant by finding another man." (Man participant)

People could tell each member of the infertile couple to "try outside". This leads to promiscuity in society and could increase risk of sexually transmitted infections.

While the social burden falls disproportionately on women, infertile men are not excluded and may not be valued as adults by their communities if they are unable to have a child and in some societies if they only have girls [2]:

He endured taunts about their childlessness: "mmmmm you-infertile man (Gocho), bring your spouse and she will have a child with us! .... Others were saying with my partner that she was just misusing me just because we have an infertility problem." (Man participant)

The women also experience torture in many settings

“... I do not want to be any near my husband's relatives just because they will subject me to all sorts of insults ... They cast all sorts of things at you that can even make you kill yourself." (Woman participant, infertile)

It has also been shown from the articles that infertility males experience the negative effects of infertility diagnosis [18]; the findings suggested that a serious diagnosis of infertility problem could destroy their marriages, 
and the relationship with community members and a man's prospects of a future father are shattered.

"It is too painful just because it has occurred when I still love her. I had the dream that I will be mulala, an elder. I had hoped to be called a father one day and to help my child in every way possible." (Man participant)

\section{Discussion}

Similar to the findings of other studies this review has shown that infertility in sub-Saharan African region and the value of children is a diverse issue other than is basically and traditionally known [19]. This has exposed infertility in its broadest terms in this region. This calls for a unified force from the whole society in as far as the view of infertility is concerned in the region.

The review also supports the view that infertility is erroneously perceived as a woman's issue in many sub-Saharan African settings with its disruptive power towards women [20]. If the fight against infertility is to be won, then all concerned must take responsibility and seek the required assistance.

The society's over valuing of children and blending those who are childless as useless in society needs to be critically looked into. It is such traditional perception that puts more pressure on concerned infertile individuals and hence denying responsibility. If clinical practice for infertility care is to improve, there is need for policy change that would break the traditional norm of viewing infertility as a nonexistent issue and if it exists then it's a woman's affair.

The perception of infertility as something that would deny an individual some community rights also requires to be changed. The individuals in the society should be given equal respect regardless to whether they have children or not. This will create room for the positive acceptance of infertility as a realistic reproductive health problem and not a punishment. In the same manner the regarding of children as source of wealth for parents when they are old, generates the unnecessary tensions in the infertile individuals as they perceive themselves to be helpless people in their old age. Society should take children as the ones who need parent's support for them to develop into successful citizens. In this regard those without children should invest the money meant for child support into something for their possible future support in old age.

The other perceptions on the causes of infertility would affect the uptake and utilization of some reproductive health services.

"Prostitute women when they were young or those who were using contraception to avoid becoming pregnant ... they become infertile and trouble their spouses, they move from hospital to hospital in search for a child." (Woman participant)

In this case linking infertility with contraceptive use would negatively affect utilization of contraception and lead to negative reproductive health effects in society. There is need for society awareness on the realistic facts of infertility causes.

The findings have also revealed the trend of health care seeking among infertile couples. Health care seeking is mainly left to women just because it is the woman who is seen carrying the pregnancy in society.

"It is us, the women who are worried with infertility just because of the pressure from society that come to us. So we go and seek for help. Husbands may not want to go for medical attention even though at times the problem could be with them but you still have to do something." (Woman participant, infertile)

This practice takes away the joint responsibility of the husband and wife for infertility and leaves it all on the woman. This in the long run creates unnecessary tensions in the woman as well as the man. The infertility problem is not viewed as a couple's problem but rather an individualistic issue between the two members of the couple and mainly the woman. It is from this background that when one member of the couple is found to have the infertility problem, divorce ensures, why? Because there is no shared responsibility. If say it is the man who has been found with the problem, the woman would run away from the man saying, I have been blamed all this time when the problem is actually your problem-I am going. Such issues need to be resolved in society if the fruits of infertility care are to be helpful. Infertility care does not mean divorce.

The findings show that the modern hospital is often the last resort for infertility health care seeking compared to the other sources of care.

"You go to hospital, and they will call that those with infertility should go there letting all the others know 
of your infertility issue. Then later you see people pointing fingers at you wherever you go." (Woman participant, infertile)

This practice by hospital health care professionals should be changed if the hospital infertility care outlets are to be utilized to their maximum. Here it is clearly shown that the behavior of health care providers is critical in as far as infertility health care seeking is concerned. Health care professionals must realize the fact that infertility is a sensitive issue especially in areas where high fertility is order of the day. This experience forces the infertile couples to seek and exhaust alternative infertility care services before visiting modern hospitals.

"Traditional healers obtain their influence from divine sources and are therefore expected to conduct their practice secretly in fear of losing their influence. But at the hospital no one cares at all." (Female participant)

This over reliance on traditional healers often times delays the infertile couples to helpful and appropriate hospital care. They visit traditional practitioners who give them all sorts of medicines and often harmful at times. When they notice they are not helping, lately they do visit the hospitals for lack of an alternative. There is need for increased awareness to reverse this situation; the hospital professionals must handle those with infertility problem with privacy. Those with the problem must realize that good care for their problem is at the hospital.

The findings have also revealed that the individuals who have a fertility problem are subjected to a lot of negative social implications. The impacts mainly emanating from the society negative perception of infertility. Worse still the insults could even be directed at those who only have female children. With such negative society perception, a lot of negative consequences follow, and the father would not love his girl children and the mother would see an eminent risk of a polygamous family or even divorce. This could also fuel the risk of sexually transmitted infections including HIV/AIDS as a result ending up with a lot of orphans in society. There is need to have such society perceptions reversed if the battle against society negative infertility perception is to be worn.

\section{Limitations}

The review has the following shortfall, relevant and latest articles $(2014,2015)$ on the topic were not forthcoming and very few, only five have been mainly included in this report.

\section{Further Research}

This review has pointed out a critical view of infertility than what it is traditionally known. It has shade more light on the diversity of it as a problem. There is urgent need for further research regarding infertility with a particular focus on male and society perception of infertility. The findings of such studies would help drive policy change on infertility perception in society and resolve its gross negative implications.

\section{Conclusions}

In Sub-Saharan Africa, children are highly valued in the society and infertility is greatly stigmatized and has negative society perception with numerous social implications. In such a setting, the concept of reproductive health should include policies which could make it possible for couples to aspire to have the number of children they wish, and also that would make couples and the whole society aware of the reality of infertility as a reproductive health problem.

Providing sexual and reproductive health education could serve as important tool which can minimize the negative society perception of infertility and possibly reduce the occurrence of gender-specific burden of infertility where men are in most cases taken out of the infertility equation. Education could as well help resolve the miss conceptions on infertility regarding its causes, treatment and health seeking behaviour. Health care systems and health care professionals should be equipped with the necessary resources and skills so that they should among many things manage infertility with the needed skill and confidentiality it deserves.

\section{References}

[1] Tabong, P.T.-N. and Adongo, P.B. (2013) Understanding the Social Meaning of Infertility and Childbearing: A Qualit- 
ative Study of the Perception of Childbearing and Childlessness in Northern Ghana. PLoS ONE, 8, e54429. http://dx.doi.org/10.1371/journal.pone.0054429

[2] Parrott, F.R. (2014) At the Hospital I Learnt the Truth': Diagnosing Male Infertility in Rural Malawi. Anthropology \& Medicine, 21, 174-188.

[3] Hollos, M. and Whitehouse, B. (2014) Women in Limbo: Life Course Consequences of Infertility in a Nigerian Community. Human Fertility (Cambridge, 17, 188-191. http://dx.doi.org/10.3109/14647273.2014.936052

[4] Asemota, O.A. and Klatsky, P. (2015) Access to Infertility Care in the Developing World: The Family Promotion Gap. Seminars in Reproductive Medicine, 33, 17-22. http://dx.doi.org/10.1055/s-0034-1395274

[5] Ghana Statistical Service (2011) Ghana Population and Housing Census Report 2010. Ghana Statistical Service, Accra.

[6] National Collaboration Centre for Women and Children Health (2012) Fertility: Assessment and Treatment for People with Fertility Problems. RCOG, London.

[7] Culley, L., Hudson, N., et al. (2013) Where Are All the Men? The Marginalization of Men in Social Scientific Research on Infertility. Reproductive Biomedicine Online, 27, 225-235.

[8] Gerrits, T. and Shaw, M. (2010) Biomedical Infertility Care in Sub-Saharan Africa: A Social Science Review of Current Practices, Experiences and View Points. Facts, Views \& Vision in ObGyn, 2, 194-207.

[9] Dhont, N., Luchters, S., et al. (2010) Gender Differences and Factors Associated with Treatment Seeking Behavior for Infertility in Rwanda. Human Reproduction, 25, 2024-2030.

[10] Horbst, V. (2010) Male Perspectives on Infertility and Assisted Reproductive Technologies (ART) in Sub-Saharan Contexts. Facts, Views \& Vision in ObGyn Monograph, 8, 22-27.

[11] Lampiao, F. (2013) It Is Time the Masses Are Sensitised That Men Too, Like Women, Have Reproductive Problems. Fanuel Lampiao Talks to Thengo Kavinya on His Career in Spermatology. Malawi Medical Journal, $25,94$.

[12] Moyo, S. (2013) Indigenous Knowledge Systems and Attitudes towards Male Infertility in Mhondoro-Ngezi, Zimbabwe. Culture Health \& Sexuality, 15, 667-679.

[13] Moyo, S. and Muhwati, I. (2013) Socio-Cultural Perspectives on Causes and Intervention Strategies of Male Infertility: A Case Study of Mhondoro-Ngezi, Zimbabwe. African Journal of Reproductive Health, 17, 89-101.

[14] Odinga, A. (2011) I Am Not Tassa, He Is Not a Man Like Other Men’: Feminising Infertility and Masculinising Fertility in South Nyanza, 1945-1960. In: Tamale, S., Eds., African Sexualities: A Reader, Pambazuka Press, Cape Town, 463-469.

[15] Donkor, E.S. and Sandall, J. (2009) Coping Strategies of Women Seeking Infertility Treatment in Southern Ghana. African Journal of Reproductive Health, 13, 81-93.

[16] Dyer, S.J. (2007) The Value of Children in African Countries-Insight from Studies on Infertility. Journal of Psychosomatic Obstetrics \& Gynaecology, 28, 69-77. http://dx.doi.org/10.1080/01674820701409959

[17] Fledderjohann, J.J. (2012) Zero Is Not Good for Me: Implications of Infertility in Ghana. Human Reproduction, 27, 1383-1390. http://dx.doi.org/10.1093/humrep/des035

[18] Dhont, N., van de Wijgert, J., et al. (2011) Results of Infertility Investigations and Follow-Up among 312 Infertile Women and Their Partners in Kigali, Rwanda. Tropical Doctor, 41, 96-101.

[19] Ibisomi, L. and Mudege, N.N. (2014) Childlessness in Nigeria: Perceptions and Acceptability. Culture Health \& Sexuality, 16, 61-75. http://dx.doi.org/10.1080/13691058.2013.839828

[20] Dimka, R.A. and Dein, S.L. (2013) The Work of a Woman Is to Give Birth to Children: Cultural Constructions of Infertility in Nigeria. African Journal of Reproductive Health, 17, 102-117. 


\section{Submit or recommend next manuscript to SCIRP and we will provide best service for you:}

Accepting pre-submission inquiries through Email, Facebook, LinkedIn, Twitter, etc.

A wide selection of journals (inclusive of 9 subjects, more than 200 journals)

Providing 24-hour high-quality service

User-friendly online submission system

Fair and swift peer-review system

Efficient typesetting and proofreading procedure

Display of the result of downloads and visits, as well as the number of cited articles

Maximum dissemination of your research work

Submit your manuscript at: http://papersubmission.scirp.org/ 